Research Article

\title{
Investigation of Anisotropic Permeability and Porosity of CJRM considering Different Confinement Loading Pressures
}

\author{
Zhiming Chao, ${ }^{1}$ Guotao $\mathrm{Ma} \mathbb{D D}^{2}{ }^{2}$ Xiewen $\mathrm{Hu},{ }^{1}$ and $\mathrm{Yuzhe} \mathrm{Zhu}^{3}$ \\ ${ }^{1}$ Faculty of Geosciences and Environmental Engineering, Southwest Jiaotong University, Chengdu 610000, China \\ ${ }^{2}$ School of Engineering, The University of Warwick, Coventry CV4 7AL, UK \\ ${ }^{3}$ School of Foreign Languages, Renmin University of China, Beijing 100872, China \\ Correspondence should be addressed to Guotao Ma; g.ma.1@warwick.ac.uk
}

Received 14 November 2019; Revised 17 May 2020; Accepted 15 June 2020; Published 3 July 2020

Academic Editor: Arnaud Perrot

Copyright (c) 2020 Zhiming Chao et al. This is an open access article distributed under the Creative Commons Attribution License, which permits unrestricted use, distribution, and reproduction in any medium, provided the original work is properly cited.

\begin{abstract}
An innovative method is proposed to prepare artificial columnar jointed rock masses (CJRM) with different columnar dip angles, and laboratory physical model tests are conducted to investigate anisotropic permeability and porosity characteristics of the prepared artificial CJRM. In the physical model experiment, permeability and porosity of artificial CJRM with different columnar dip angles is measured during three times cyclic loading and unloading of confinement pressure. Based on the results of the laboratory model tests, the Equivalent Continuum Media Model was applied to analyse anisotropic permeability of CJRM. The main conclusions are summarized as follows. In the first loading phase of confinement pressure, the impacts of confinement pressure on the anisotropic permeability of artificial CJRM, porosity, and the major and minor principle permeability coefficients (PPCs) are significant, while in the following stages of confinement pressure loading and unloading, the change of them is small, with stable value. Permeability of artificial CJRM gradually increases with rise of columnar dip angle, and the permeability anisotropy of artificial CJRM under low confinement pressure is higher than that under low confinement pressure.
\end{abstract}

\section{Introduction}

Columnar jointed rock masses (CJRM) as a type of jointed rock masses with distinct fractural structure that are developed due to the cooling shrinkage in the process of the overflow and eruption of volcanic lava are frequently encountered in civil and hydraulic engineering projects [1]. For instance, CJRM are identified in dam foundation and abutment of Baihetan hydropower station in southwest China, which has significant impacts on the stability of the dam.

Due to the presence of columnar joint structure, permeability properties of CJRM have significant anisotropy, which means that the permeability of CJRM is different along the direction of columnar dip angle [2]. Under certain extreme conditions, such as flooding and rainstorm, fluid is permeated into CJRM mainly through the major seepage channels of columnar joints, while the permeability of intact rock is extremely low, diminishing the strength of CJRM and causing potential geohazards, which decreases significantly their stability [3]. Owing to the anisotropic permeability of CJRM, along the different directions of columnar dip angle, the seepage volume of fluid into CJRM is diverse, which causes the stability difference of CJRM along the direction of column dip angle [4]. Hence, in order to correctly assess the stability of CJRM and take proper protection measures to avoid the occurrence of engineering disasters related to CJRM, the research about anisotropic permeability of CJRM is nonnegligible.

In practical engineering projects, CJRM often bear cyclic loading and unloading of confinement pressure [5]. Taking Baihetan hydropower station as an example, as a hydropower plant with high impounding water level, in the impounding process, columnar joints are closed under the effect of high hydraulic pressure, while in the process of discharging water, the columnar joints are open due to the decrease of hydraulic pressure [6]. The repeated impounding and discharging water causes the cyclic loading and 
unloading of confinement pressure on CJRM, which has nonnegligible influence on the anisotropic permeability properties of CJRM [7]. However, currently, the investigation about anisotropic permeability characteristics of CJRM during cyclic loading and unloading of confinement pressure has not been reported. It is worthy to explore the change of anisotropic permeability of CJRM during cyclic loading and unloading of confinement pressure.

Anisotropic permeability of CJRM is difficult to be investigated by adopting regular methods due to the special geostructure of CJRM. More importantly, most of the existing approaches cannot consider the impacts of cyclic loading and unloading of confinement pressure on of CJRM $[8,9]$. Laboratory tests on natural CJRM do not sufficiently reflect the anisotropic permeability properties of CJRM. This is because CJRM have multisets of joints with large volume, but the natural rock core sample that is taken from the site seldom contains joints or only has one set of joints [10]. Another problem which is the large discrepancy between hidden joints in natural CJRM causes the large discreteness of laboratory experimental results [11]. Site experiments such as pumping tests and packer tests are often conducted by some researchers to investigate the permeability tensor of rock masses [12-14]. Due to the high heterogeneity and anisotropy of CJRM, if pumping tests or packer tests are applied to measure the anisotropic permeability of CJRM, the test wells need to be placed in different directions and different locations, which is extreme costly and time-consuming [15]. The analytical solution is another popular method to research the permeability of rock masses [16-18]. The analytical solution approach assumes that the permeability tensor of rock masses is obtained by conducting simply permeability superposition of individual joints and intact rock matrix [19]. The interconnection of joints and fluid flow transportation between joints and rock matrix are ignored. However, for CJRM, the geometrical morphology of columnar joints is complex and the quantity of fluid exchanges between joints is large, which impacts greatly the value of permeability tensor for CJRM, which cannot be ignored. In recent years, the numerical simulation methods such as Finite Element Method (FEM) and Discrete Element Method (DEM) are often adopted by some scholars to explore permeability properties of rock masses [20-22]. However, CJRM are highly jointed, which is hardly dealt by using FEM due to the limitation of mesh generation. For the application of DEM in analysing the permeability properties of CJRM, it requires a large number of mechanical parameters of CJRM but now the research about the mechanical properties of CJRM is rare [23]. It is difficult to obtain the large number of mechanical parameters of CJRM for DEM modelling. Moreover, due to the interconnectivity between joints and the geological complexity of discontinuities for CJRM, both of FEM and DEM face the computational complicacy for conducting numerical simulation on the permeability characteristics analysis of CJRM, especially for the numerical operation that is conducted under different stress conditions [24, 25].

Physical model tests on rock-like analogue model materials provide an alternative approach to investigate anisotropic permeability properties of CJRM [26]. To physical model test, the joint parameters are easy to control, and the reproducibility is also a big advantage. The specimens are more homogeneous and easier to reproduce. Also, specimens with different dip angles can be obtained easily, and the anisotropic permeability of CJRM can be obtained effortlessly by measuring the permeability of CJRM with different columnar dip angles [6]. Additionally, the rock-like analogue model materials of CJRM have been adopted by some scholars to research the mechanical properties of CJRM [27]. It has been proved that rock-like analogue model materials can simulate CJRM, and physical model tests are an effective way to explore the characteristics of CJRM.

In order to understand comprehensively anisotropic permeability behavior of CJRM, a sound comprehension of the changing rules of CJRM porosity during cyclic loading of confinement pressure is indispensable because internal pore structure of CJRM is a key factor to influence permeability of CJRM $[28,29]$. Hence, the investigation about the changing law of CJRM porosity during cyclic loading and unloading of confinement pressure is also necessary to be conducted to explore the internal mechanism of anisotropic permeability variation of CJRM.

To cover the deficiency, in this paper, firstly, an innovative method is proposed to prepare artificial CJRM with different columnar dip angles, and laboratory physical model tests are conducted to investigate the anisotropic permeability and porosity characteristics of the prepared artificial CJRM. In the physical model experiment, the anisotropic permeability and porosity of artificial CJRM is measured during cyclic loading and unloading of confinement pressure. Then, based on the results of the physical model experiment, the anisotropic permeability and porosity change law of artificial CJRM during cyclic loading and unloading of confinement pressure is researched. After that the internal mechanism analysis of the relationship between anisotropic permeability of CJRM and cyclic loading and unloading of confinement pressure is conducted based on the measured porosity. Finally, based on results of the physical model tests, Equivalent Continuum Media Model is utilised to analyse the permeability properties of CJRM.

\section{Geological Structure of the Natural CJRM}

The formation mechanism of CJRM in volcanic lava flow is that, during the cooling process of rock flow, the flat lava condensation surface forms numerous regular and irregularly spaced shrinkage centers, resulting in tension cracks that are perpendicular to the shrinkage direction [30]. Then, volume shrinkage towards the shrinkage centers causes rock masses to split, forming hexahedral, quadrilateral, and septilateral cylinders [31]. CJRM are detected in Baihetan hydropower station that is located between Ningnan Country of Sichuan Province and Qiaojia County of Yunnan Province downstream of Jinsha River, China, as shown in Figure 1 . The power supply capacity of the hydropower station is $16,000 \mathrm{MW}$, which is the core power source for the west-to-east power transmission project in China, which will 


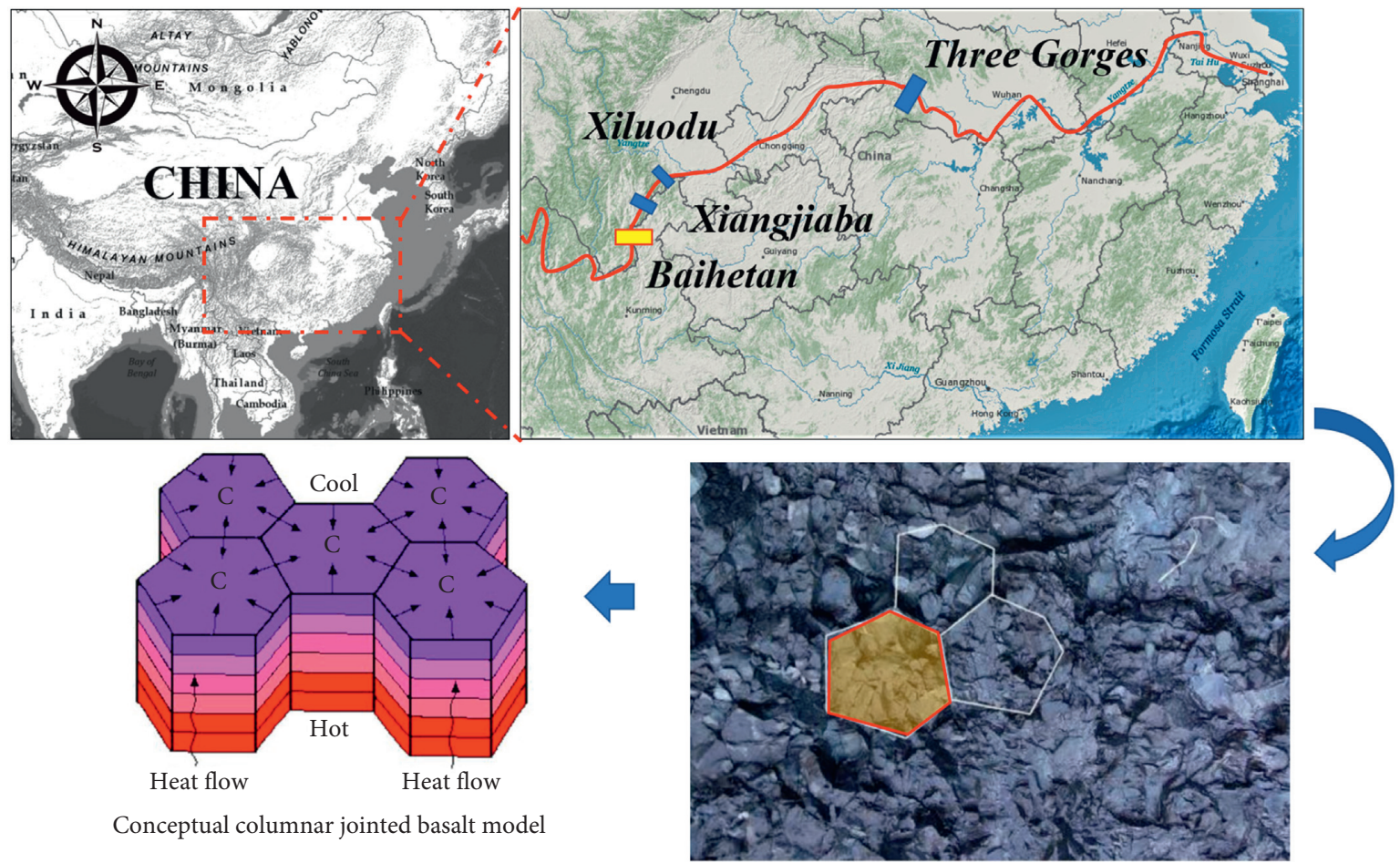

FIGURE 1: The location map and geological cross section of CJRM.

be the third largest hydropower plant in the world. CJRM in Baihetan hydropower station are mainly distributed in riverbed, dam foundation, and dam abutment in right bank. Columnar joints in the CJRM are slender, exhibiting obviously isotropic characteristics, as shown in Figure 1.

\section{Experimental Methods}

3.1. The Preparation of Sample. In this work, the regular hexagon with $6 \mathrm{~mm}$ length of side and $180 \mathrm{~mm}$ length of column height is adopted to simulate actual columns by adopting the material moulding mould and the material adding mould, and cement mortar is adopted to prepare the hexagon columns. The adopted cement mortar is mixed by ordinary Portland cement, natural river sand, and water based on the weight proportion of $1: 0.5: 0.4$. In order to improve antiseepage properties and fluidity of cement mortar, permeability-reducing agent and waterreducing agent that account for $0.2 \%$ of total mass are added into cement mortar. Additionally, little defoamer is used to reduce bubble that is produced during the hydration process of cement. The detailed preparing process is as follows.

Firstly, the two parts of mould are hold up correspondingly. Then, every groove in the material forming mould is filled with the prepared cement mortar by adopting the material adding device. After that, the material forming mould is moved to the constant temperature $28^{\circ} \mathrm{C}$ and humility $95 \%$ environment, and the mould is disassembled next day, as shown in Figure 2. The process is repeated until enough regular hexagon columns are attained. The attained normal hexagon columns are put into the constant temperature $28^{\circ} \mathrm{C}$ and humility $95 \%$ environment to maintain for 30 days. After that, the normal hexagon columns are bonded to columnar jointing rock mass models by the mixture of white cement and water with the mass ratio 1 : 0.4, as shown in Figure 3. Then, the columnar jointing rock mass blocks are packed and sealed by plastic membrane and put into the constant temperature $28^{\circ} \mathrm{C}$ and humility $95 \%$ environment to maintain for 30 days. In the end, the columnar jointing blocks are cut and polished to diameter $50 \mathrm{~mm} \times$ height $50 \mathrm{~mm}$ of artificial CJRM with columnar dip angles $0^{\circ}, 20^{\circ}, 40^{\circ}, 50^{\circ}, 70^{\circ}, 80^{\circ}$, and $90^{\circ}$; the parameters of the artificial CJRM are shown in Table 1.

3.2. Experimental Apparatus. Due to the extremely low permeability of artificial CJRM, it needs a really long time for liquid to penetrate through artificial CJRM, when liquid is adopted as seepage media to measure permeability of artificial CJRM. During the long measurement time, experimental precision is unavoidable to be impacted by the variation of external factors such as temperature and humility, which causes significant errors on experimental results. Hence, in this experiment, gas is adopted as seepage media to measure permeability of artificial CJRM, which can penetrate through artificial CJRM in short time, obtaining permeability of artificial CJRM. The gas permeability test system, as shown in Figure 4, was utilised to measure the permeability of artificial CJRM. Meanwhile, porosity of artificial CJRM is measured by the experimental device. The experiment device is composed of rock core pressure chamber, confining pressure regulating device, seepage pressure regulating device, upstream and downstream gas 


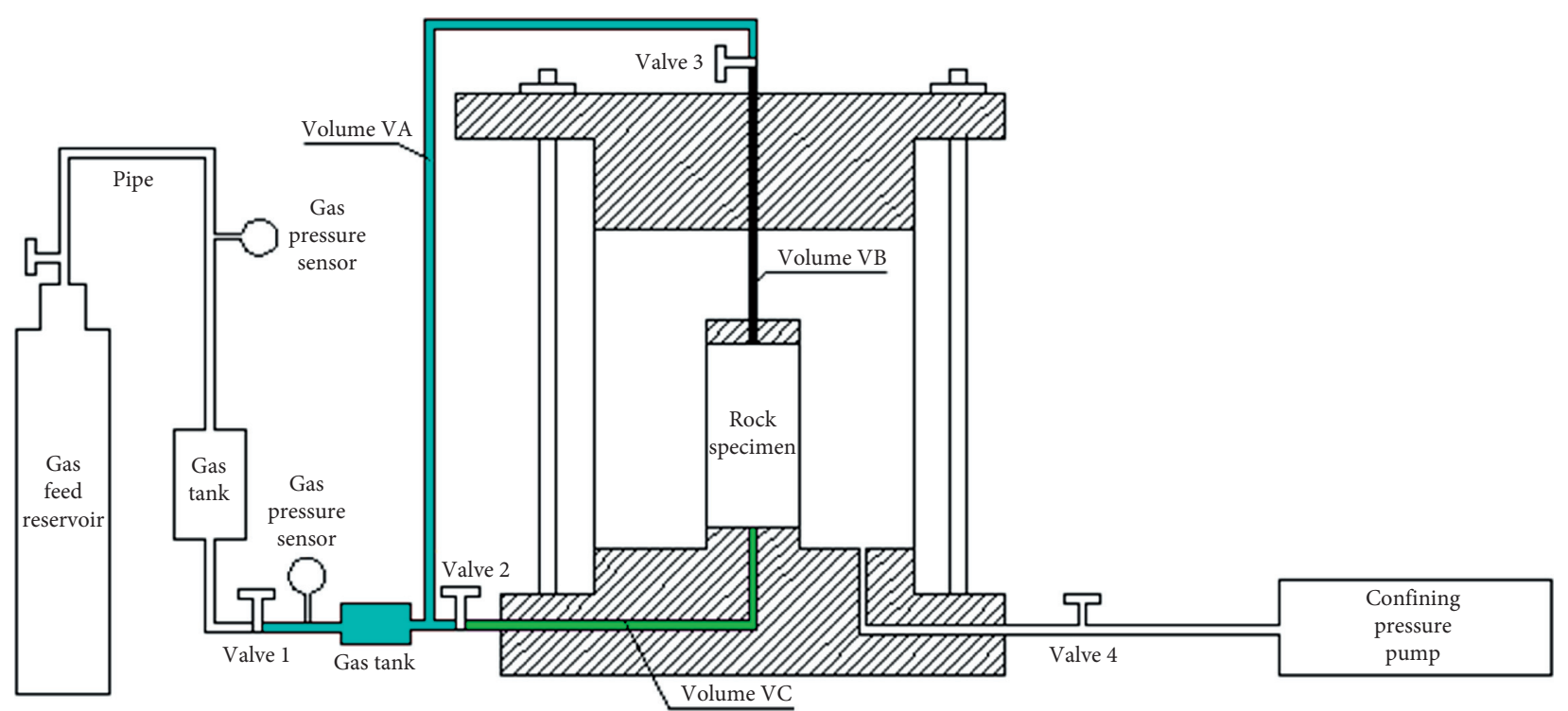

FIGURE 2: Diagram of measuring sample porosity.

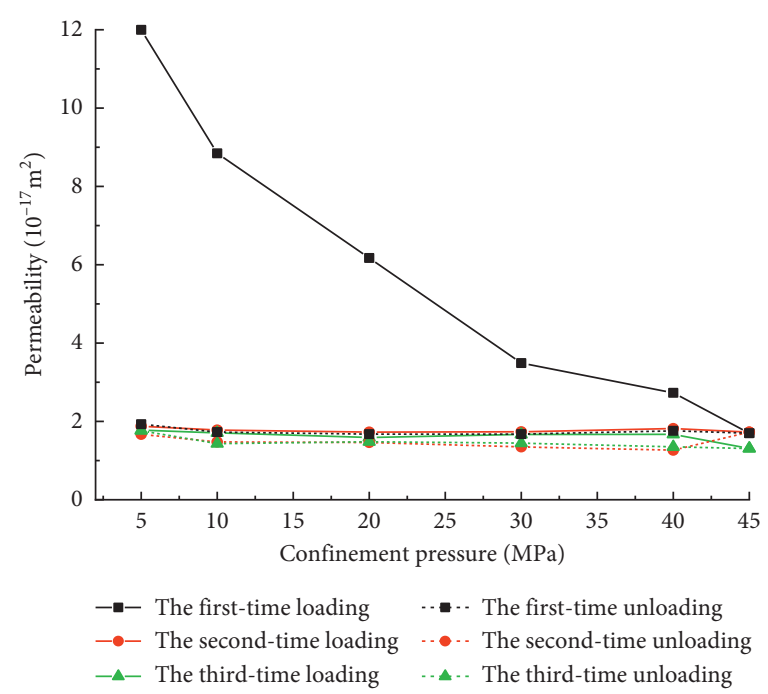

(a)

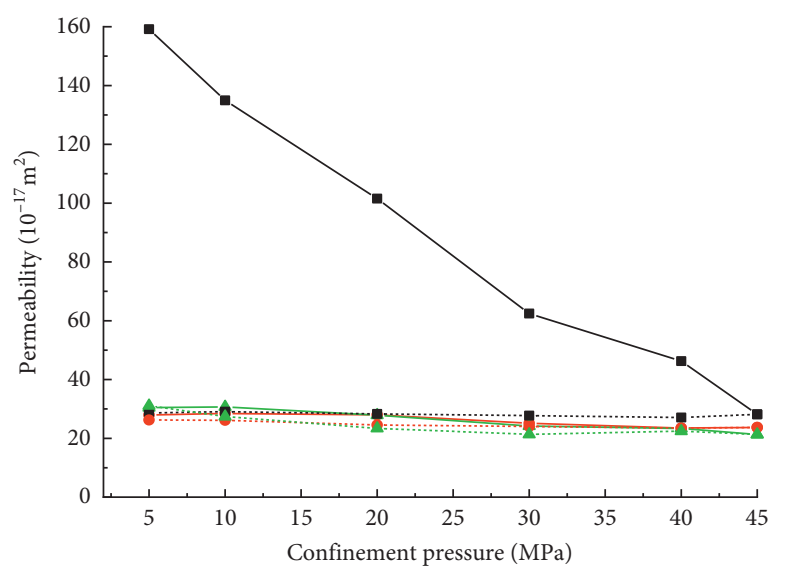

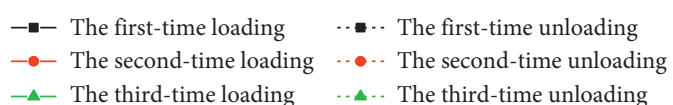

(c)

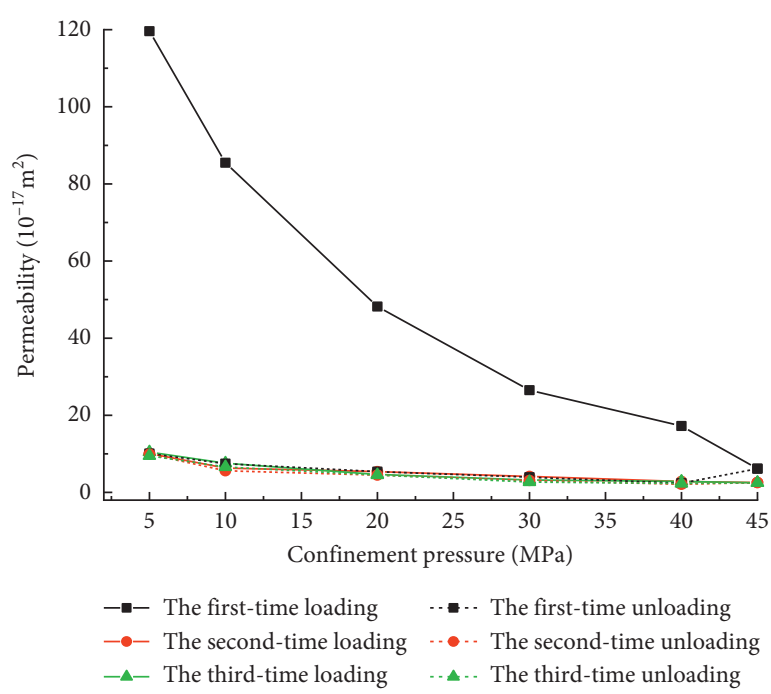

(b)

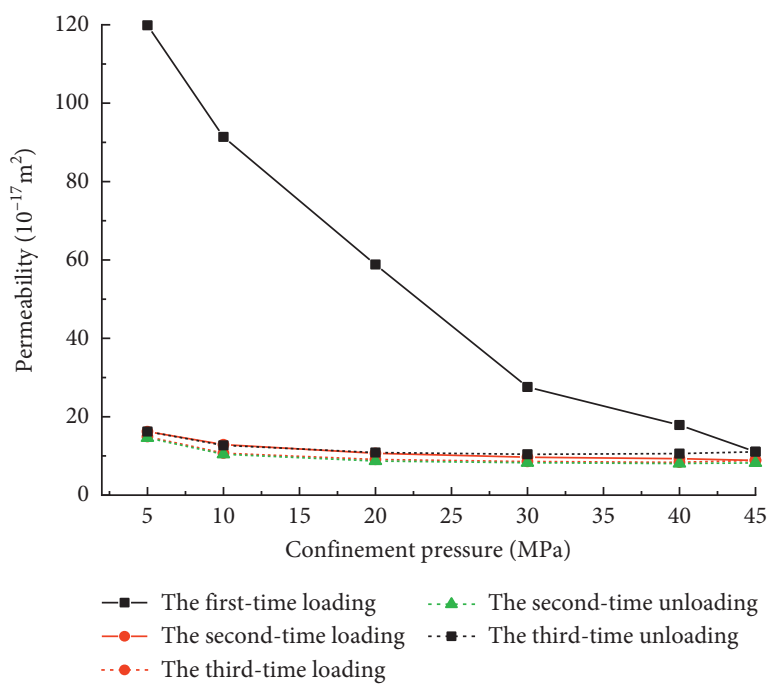

(d)

Figure 3: Continued. 


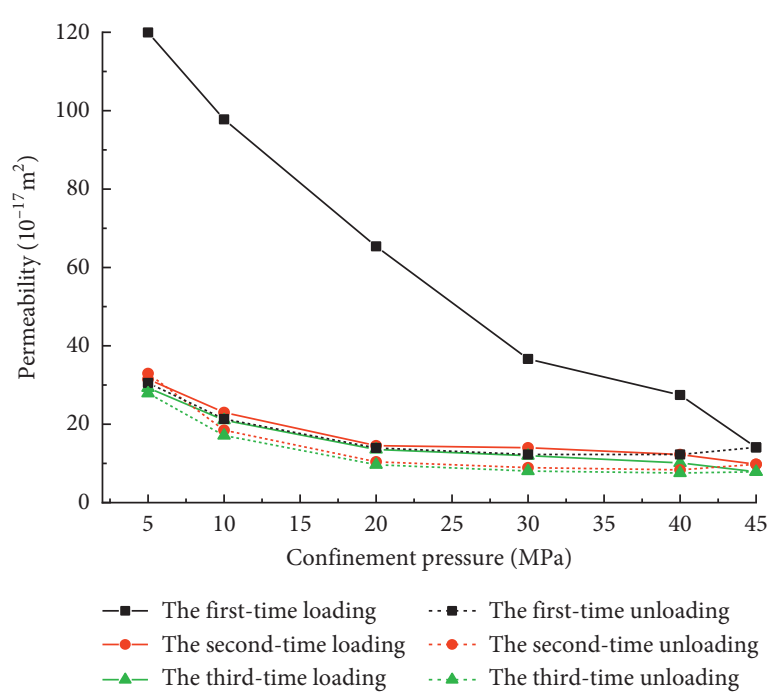

(e)

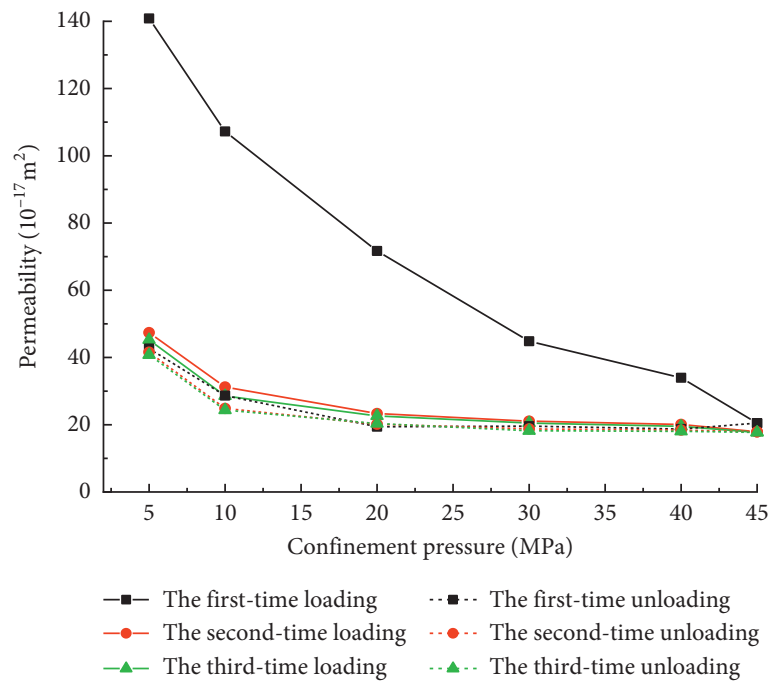

(g)

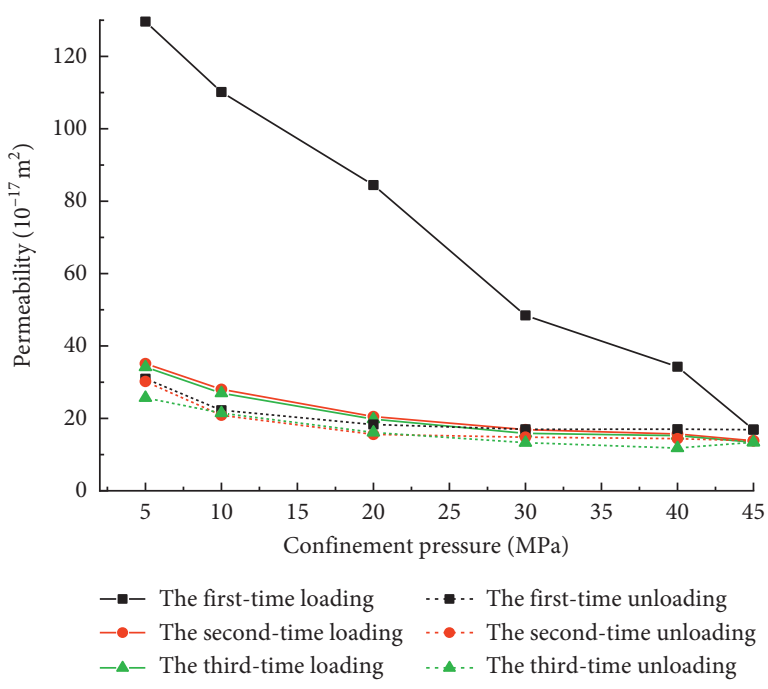

(f)

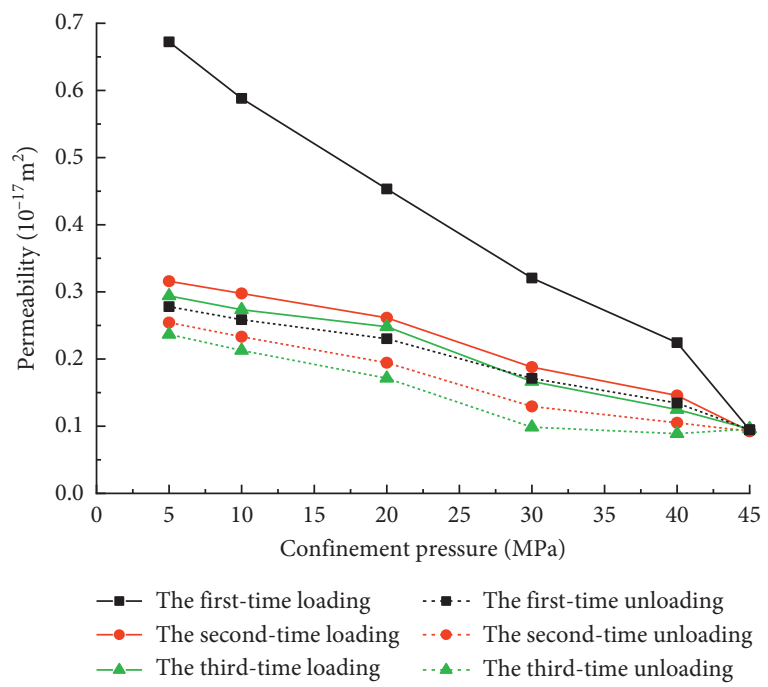

(h)

FIgURE 3: The evolution law of the permeability of artificial CJRM with different columnar dip angles during cyclic loading and unloading of confinement pressure. (a) $0^{\circ}$ columnar dip angle. (b) $20^{\circ}$ columnar dip angle. (c) $40^{\circ}$ columnar dip angle. (d) $50^{\circ}$ columnar dip angle. (e) $70^{\circ}$ columnar dip angle. (f) $80^{\circ}$ columnar dip angle. (g) $90^{\circ}$ columnar dip angle. (h) Intact rock sample.

TABLE 1: Parameters of artificial CJRM table.

\begin{tabular}{|c|c|c|c|c|c|c|}
\hline Number & Inclination angle $\left({ }^{\circ}\right)$ & Mass (g) & Diameter $(\mathrm{mm})$ & Height $(\mathrm{mm})$ & Volume $\left(\mathrm{cm}^{3}\right)$ & Density $\left(\mathrm{g} / \mathrm{cm}^{3}\right)$ \\
\hline $\mathrm{v}-1$ & 0 & 200.52 & 50.64 & 50.63 & 99.34 & 2.08 \\
\hline $\mathrm{v}-2$ & 20 & 201.32 & 50.36 & 50.24 & 101.91 & 2.01 \\
\hline $\mathrm{v}-3$ & 40 & 204.06 & 50.06 & 50.26 & 102.36 & 2.03 \\
\hline $\mathrm{v}-4$ & 50 & 206.46 & 50.09 & 50.27 & 104.51 & 2.03 \\
\hline $\mathrm{v}-5$ & 70 & 202.57 & 50.39 & 50.14 & 102.83 & 2.01 \\
\hline$v-6$ & 80 & 200.46 & 50.19 & 51.83 & 102.36 & 2.00 \\
\hline $\mathrm{v}-7$ & 90 & 206.89 & 50.24 & 50.36 & 99.69 & 2.06 \\
\hline
\end{tabular}

pressure controlling panels, pressure monitor, and gas pressure gauge with high accuracy. The core holder is hydrostatic, and the way that it applies the confining pressure is equal radial and axial directions. The maximum confinement pressure of the experimental device is $60 \mathrm{MPa}$, and the maximum seepage pressure of the experimental device is $2 \mathrm{MPa}$. The accuracy of measuring gas permeability of sample is $10^{-24} \mathrm{~m}^{2}$. 


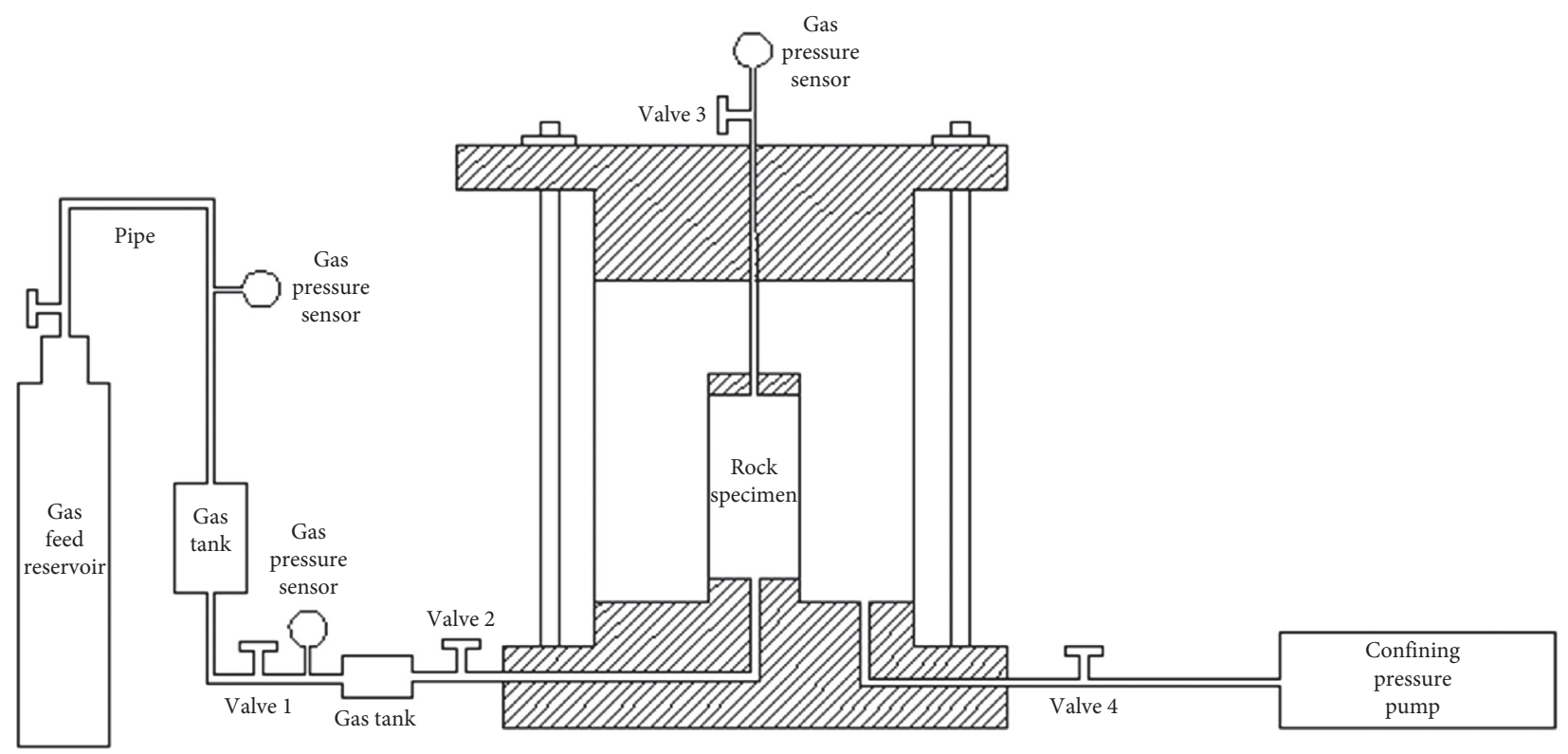

FIgURE 4: The schematic diagram of the permeability and porosity test system.

3.3. Permeability Measurement Method and Principle. Gas Flow Method is adopted in this experiment to measure permeability of artificial CJRM. Argon is adopted as the seepage media; the principle diagram of Gas Flow Method is shown in Figure 5. In Figure 5, the outlet end is open to atmospheric. Permeability of sample is calculated based on (1). The steady state flow time is 5 minutes under each loading condition. The reasons for utilising Argon are as follows. Firstly, Argon is inert gas, which can avoid the chemical reaction between Argon and specimens during the measurement process. Secondly, Argon is nontoxic gas, which can guarantee the safety of operators. Thirdly, compared with $\mathrm{N}_{2}$ and $\mathrm{He}$, Argon is low-cost, and it is fundsaving for applying Argon in experiments.

$$
k=\frac{2 Q \mu L P_{0}}{A\left(P^{2}-P_{0}^{2}\right)}
$$

where $k$ is gas permeability of sample; $\mu$ is viscosity of Argon; $P$ is gas pressure of the air inlet of pressure chamber; $P_{0}$ is atmospheric pressure, and its value is $0.1 \mathrm{MPa} ; A$ is crosssectional area of specimen; $L$ is length of specimen; and $Q$ is gas flow of air outlet of pressure chamber.

$Q$ is calculated based on

$$
Q=\frac{v \Delta P}{t\left(P_{0}+(\Delta P / 2)\right)},
$$

where $v$ is the internal volume of gas pressure gauge and its value is $0.8 C L$ and $\triangle P$ is the reading of gas pressure gauge during the time period of $t$.

3.4. Porosity Measurement Method and Principle. In this experiment, Gas Expansion Method is adopted to measure porosity of artificial CJRM by using the permeability measurement system [32]. The detailed process and principle of Gas Expansion Method are as follows.

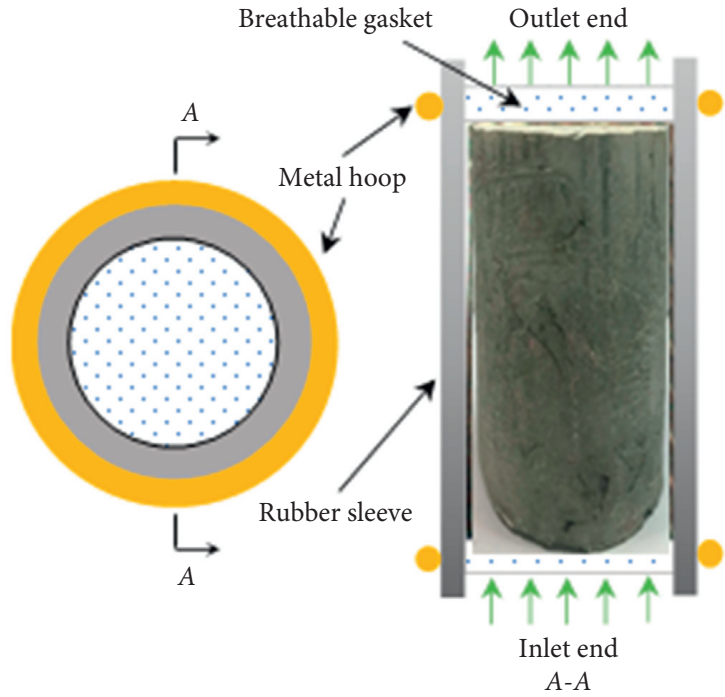

Figure 5: The schematic diagram of Gas Flow Method.

Based on Figure 2, $V_{1}$ is the volume of the external tube (blue), $V_{2}$ is the volume of the bottom air inlet tube (green), and $V_{3}$ is the volume of the upper air outlet tube (black). $V_{1}$ and $V_{2}+V_{3}$ are known. Firstly, test sample is installed into the pressure chamber. Then, Valve 5 and Valve 4 are closed, and Valve 1, Valve 2, and Valve 3 are open. After Argon flows into the pressure chamber, Valve 3 is closed. When reading of gas pressure gauge is stabilized, reading of gas pressure gauge is recorded as $P_{1}$. After that, Valve 4 and Valve 5 are open. When reading of gas pressure gauge is stabilized again, reading of gas pressure gauge is recorded as $P_{2}$. Afterwards, based on Boer Theorem, pore volume of test sample is obtained by adopting (3). Finally, according to (4), porosity of test sample is got. One has 


$$
P_{1} V_{1}=P_{2}\left(V_{1}+V_{2}+V_{3}+V_{v}\right),
$$

where $V_{v}$ is the volume of pore in sample.

$$
\varphi=\frac{V_{v}}{V} \times 100 \%,
$$

where $V$ is the volume of sample and $\varphi$ is porosity.

3.5. Test Scheme. By employing the permeability test system, the permeability of CJRM sample with 7 different column dip angles, $0^{\circ}, 20^{\circ}, 40^{\circ}, 50^{\circ}, 70^{\circ}, 80^{\circ}$, and $90^{\circ}$, during threetime cyclic loading and unloading of confinement pressure is measured by adopting Gas Flow Method. Meanwhile, porosity of artificial CJRM is measured by adopting Gas Expansion Method; the specific experimental scheme is shown in Table 2. In order to avoid experimental errors that are caused by the discreteness of sample, three repetitive tests are conducted on artificial CJRM, and the average value of the three repetitive tests is taken as the final experimental results.

\section{The Analysis of Experiment Results}

4.1. The Evolution Law of Permeability of CJRM during Cyclic Loading and Unloading of Confinement Pressure. According to the results of the physical model experiments, the evolution law of the permeability of artificial CJRM with different columnar dip angles during cyclic loading and unloading of confinement pressure is drawn, as shown in Figure 3.

According to Figure 3, in the first loading phase of confinement pressure, permeability of artificial CJRM with different columnar dip angles decreases significantly with the increase of confinement pressure. After the unloading of confinement pressure, permeability of artificial CJRM increases slightly. In the following phases of loading and unloading of confinement pressure, the relationship curves between permeability of artificial CJRM with different columnar dip angles and confinement pressure are nearidentical, and the impact of confinement pressure loading and unloading on permeability of artificial CJRM is tiny.

For the intact artificial rock, in the loading process, permeability of intact artificial rock is much smaller than that of artificial CJRM. Additionally, the decreasing magnitude of intact rock sample permeability during loading of confinement pressure is much lesser than that of artificial CJRM. Besides, unlike artificial CJRM, the relationship curves between permeability of artificial intact rock sample and confinement pressure in the following stages of confinement pressure loading and unloading are not overlapped, which gradually moves downwards with loading and unloading of confinement pressure. It demonstrates that artificial intact rock sample is not fully compacted during the first loading of confinement pressure, and it becomes gradually dense in the following loading and unloading of confinement pressure.

In order to quantitatively analyse the recovery degree of permeability of artificial CJRM after confinement pressure unloading, the ratio between the permeability under $3 \mathrm{MPa}$

\begin{tabular}{|c|c|c|c|c|}
\hline $\begin{array}{l}\text { Sample } \\
\text { number }\end{array}$ & $\begin{array}{l}\text { Loading and } \\
\text { unloading of } \\
\text { confinement } \\
\text { pressure } \\
(\mathrm{MPa})\end{array}$ & $\begin{array}{c}\text { Seepage } \\
\text { pressure } \\
(\mathrm{MPa})\end{array}$ & $\begin{array}{l}\text { Permeability } \\
\text { measurement } \\
\text { method }\end{array}$ & $\begin{array}{c}\text { Porosity } \\
\text { measurement } \\
\text { method }\end{array}$ \\
\hline $\begin{array}{l}\mathrm{T}-1 \\
\mathrm{~T}-2\end{array}$ & & & & \\
\hline $\begin{array}{l}\text { T-3 } \\
\text { T-4 } \\
\text { T-5 } \\
\text { T-6 } \\
\text { T-7 }\end{array}$ & $\begin{array}{l}5,10,20,30 \\
40,45,40,30 \\
\quad 20,10,5\end{array}$ & 1.5 & $\begin{array}{l}\text { Gas Flow } \\
\text { Method }\end{array}$ & $\begin{array}{c}\text { Gas } \\
\text { Expansion } \\
\text { Method }\end{array}$ \\
\hline
\end{tabular}

TABLE 2: Experimental scheme.

confinement pressure in the first-time confinement pressure loading and the permeability under $3 \mathrm{MPa}$ confinement pressure in the first-time confinement pressure unloading is taken as the indicator for reflecting the recovery degree of artificial CJRM permeability after confinement pressure unloading, as shown in Table 3.

Based on Table 3, the recovery degree of permeability of artificial CJRM with different columnar dip angle is all below $40 \%$. More specifically, with growth of columnar dip angle, the recovery degree of permeability rises. It demonstrates that, due to the existence of columnar joint structure, permeability of artificial CJRM is become difficult to recover to original value after confinement pressure unloading.

\subsection{The Relationship between Permeability and Columnar Dip} Angle. According to the results of the physical model experiments, the relationship between permeability of artificial CJRM and columnar dip angle under different stages of cyclic loading and unloading of confinement pressure is drawn, as shown in Figure 6.

In the different phases of three times loading and unloading of confinement pressure, permeability of artificial CJRM all gradually increases with rise of columnar dip angle. More specifically, in the stage of the first confinement pressure loading, during confinement pressure loading, the decreasing magnitude of artificial CJRM material permeability with increase of columnar dip angle falls; during confinement pressure unloading, the decreasing magnitude of artificial CJRM material permeability with increase of columnar dip angle rises. In the following stages of loading and unloading of confinement pressure, the relationship curves between permeability of artificial CJRM and columnar dip angle are nearly identical. The changing magnitude of permeability with increase of columnar dip angle is small compared with that in the stage of the first confinement pressure loading. The permeability of artificial CJRM material under the loading stage is almost the same as that under the same confinement pressure in the unloading stage. The permeability hysteresis is much smaller than that in the first-time confinement pressure loading and unloading. It demonstrates that, with loading of confinement pressure, the permeability anisotropy of artificial CJRM becomes less obvious. In the following phases of loading and unloading of confinement pressure, the permeability anisotropy of artificial 
TABLE 3: Recovery degree of the permeability of artificial CJRM with different columnar dip angles.

\begin{tabular}{lcccccccc}
\hline Columnar dip angle $\left({ }^{\circ}\right)$ & 0 & 20 & 40 & 50 & 70 & 80 & 90 & Artificial intact rock masses \\
\hline Recovery degree $(\%)$ & 16 & 19 & 20 & 27 & 34 & 39 & 40 & 46
\end{tabular}

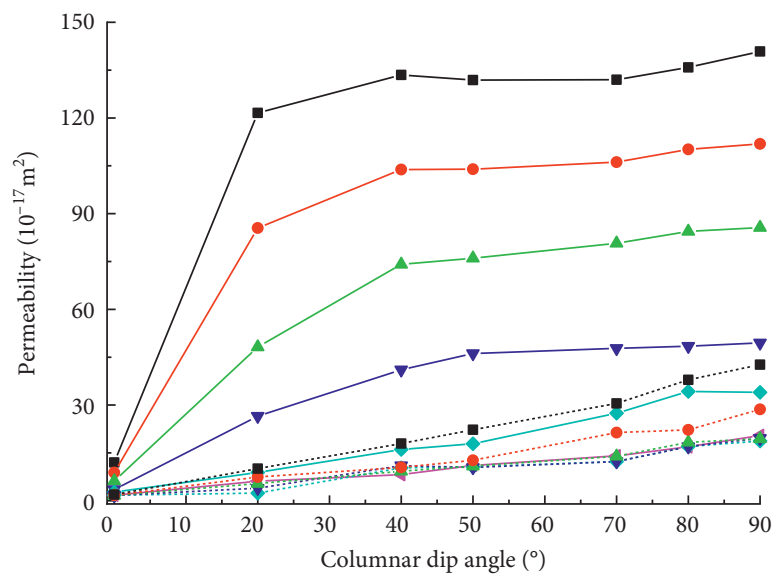

Confinement pressure

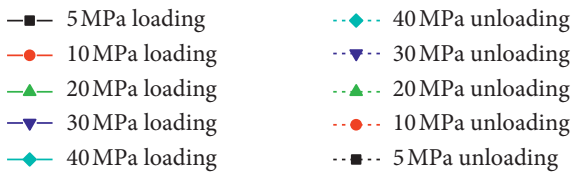

(a)

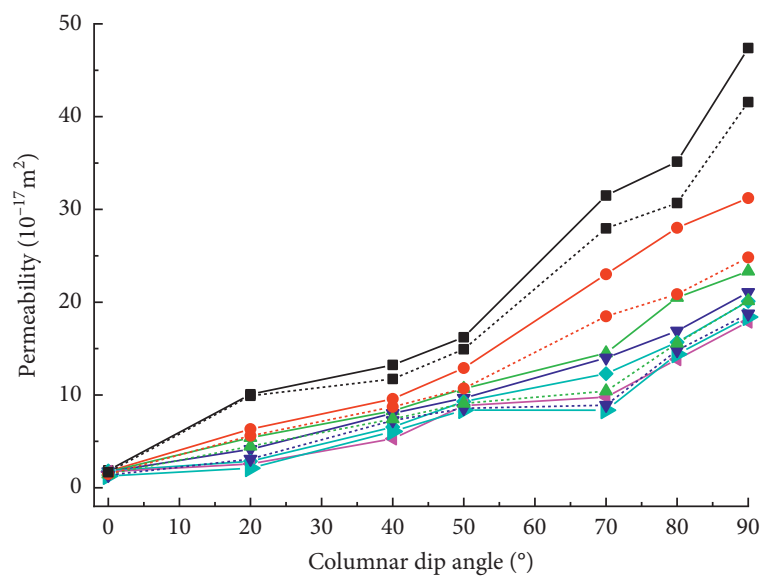

Confinement pressure

- $5 \mathrm{MPa}$ loading

- $10 \mathrm{MPa}$ loading

$-\Delta-20 \mathrm{MPa}$ loading

$-\boldsymbol{\nabla}-30 \mathrm{MPa}$ loading

$\longrightarrow-40 \mathrm{MPa}$ loading

$-445 \mathrm{MPa}$ loading

(b)
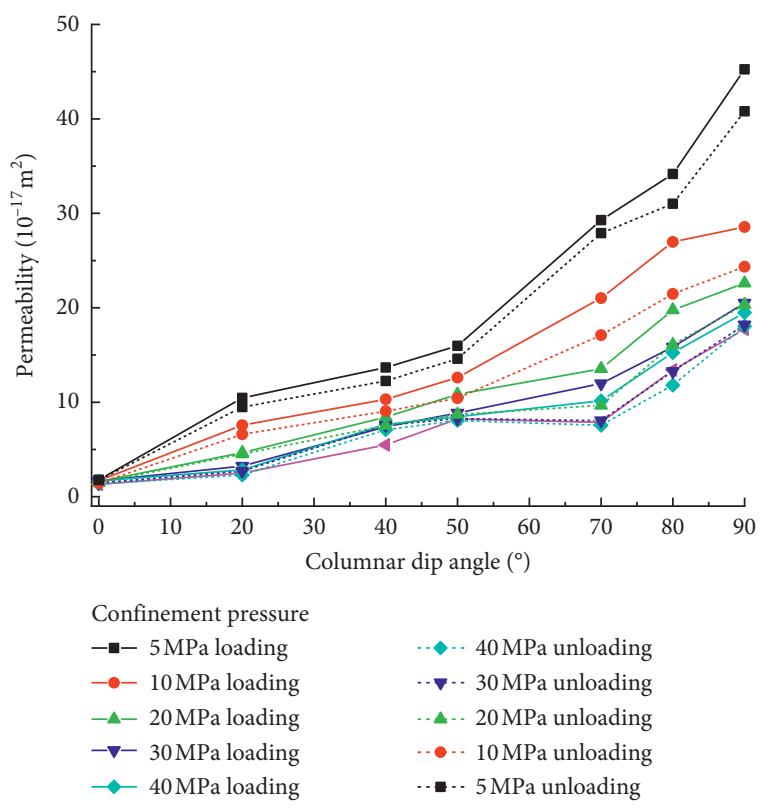

(c)

FIGURE 6: The relationship curves between permeability of artificial CJRM and columnar dip angle. (a) The first-time loading and unloading. (b) The second time loading and unloading. (c) The third time loading and unloading.

CJRM is nonsignificant. Additionally, in the stage of the firsttime loading and unloading of confinement pressure, the permeability hysteresis is large, while in the following stages of loading and unloading of confinement pressure, the permeability hysteresis is marginal.
4.3. The Relationship between Porosity and Confinement Pressure. Based on experimental results, the values of porosity of artificial CJRM with different columnar dip angles are close, and the changing rules of porosity of artificial CJRM with different columnar dip angles and confinement 
pressure are identical. Hence, the average value of porosity of artificial CJRM with different dip angles is adopted to research the changing rules between artificial CJRM porosity and confinement pressure. The relationship curves between average porosity of artificial CJRM and confinement pressure are drawn, as shown in Figure 7, and the relationship curves between porosity of intact rock sample and confinement pressure are also drawn as reference, as shown in Figure 7.

Based on Figures 7 and 8, in the stage of the first-time confinement pressure loading and unloading, porosity of artificial CJRM materials reduces significantly during confinement pressure loading, and with unloading of confinement pressure, porosity has slight increases. In the following stages of confinement pressure loading and unloading, porosity of artificial CJRM has marginal fluctuation during loading and unloading of confinement pressure, but in general, the porosity of artificial CJRM material keeps stable, with low values. It demonstrates that artificial CJRM is compacted after the first-time confinement pressure loading, and the compacted state keeps after unloading of confinement pressure. The following confinement pressure loading and unloading have small impacts on porosity of artificial material, and artificial CJRM material is kept in compacted status.

In contrary, decreasing magnitude of porosity of intact artificial rock sample is lesser than that of artificial CJRM, but with unloading of confinement pressure, increasing magnitude of porosity of intact artificial rock sample is larger than that of artificial CJRM. Additionally, unlike the relationship curves between porosity of artificial CJRM and confinement pressure, the relationship curves between porosity of intact artificial rock sample and confinement pressure gradually move downwards during the following loading and unloading of confinement pressure, which means that, in the stages of the following loading and unloading of confinement pressure, intact rock sample is further compacted continually. It demonstrates that, due to the existence of columnar joint structure, rock becomes easy to be compacted during the first-time loading of confinement pressure, and with unloading of confinement pressure, artificial CJRM keeps compacted status. In the following stages of confinement pressure loading and unloading, the artificial CJRM is not further compacted.

\section{Discussion}

In this section, Equivalent Continuum Media Model is adopted to analyse the anisotropic permeability properties of CJRM. In Equivalent Continuum Media Model, the anisotropic permeability characteristics of sample are described by the permeability tensor [9]. In this study, CJRM is taken as transversally isotropic material, which indicates that the permeability anisotropy along the plane of rock strata is ignored and only the permeability anisotropy along the dip direction of joints is considered. More specifically, the transversal isotropy means that there is an axial line through CJRM and the permeability properties

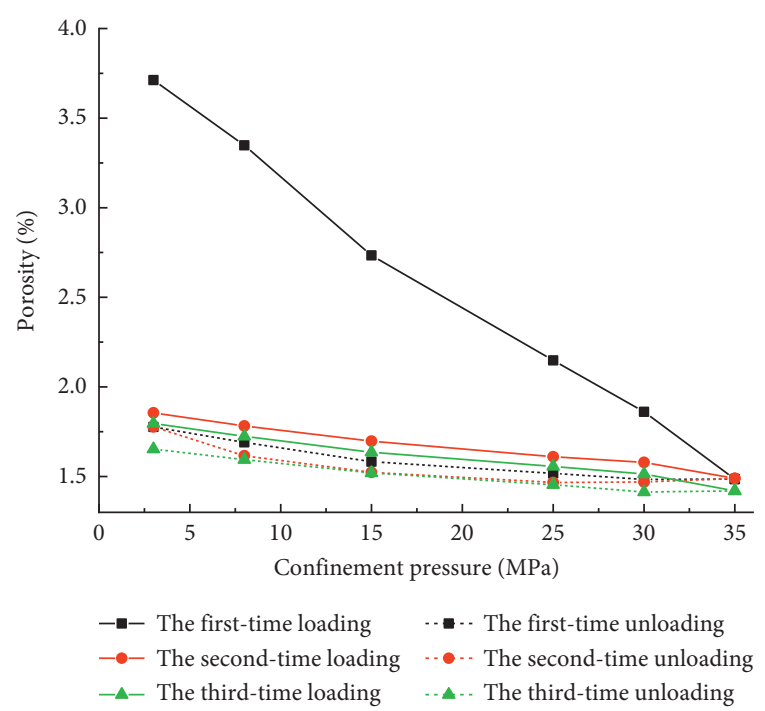

FIgURE 7: The relationship curves between porosity of artificial CJRM and confining pressure.

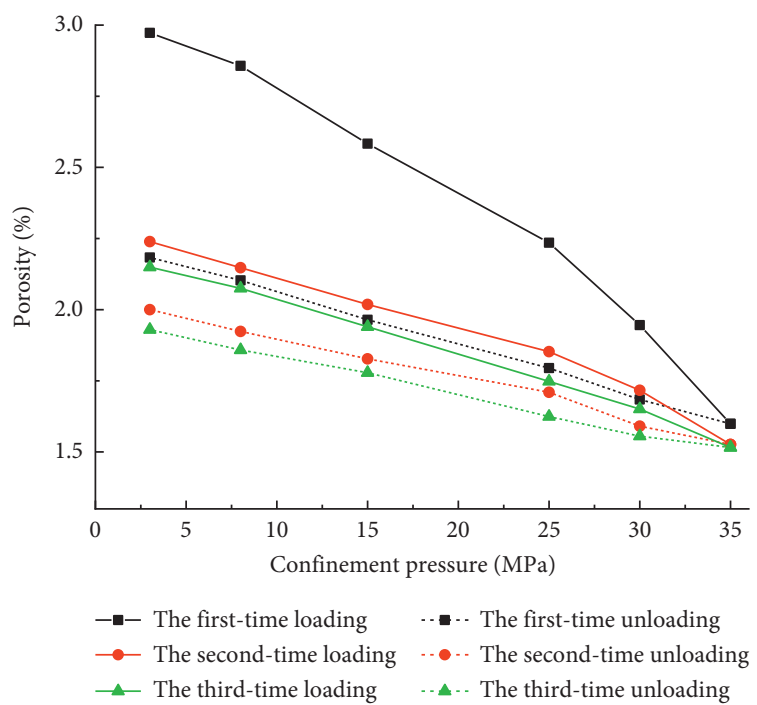

FIGURE 8: The relationship curves between porosity of artificial intact rock masses and confining pressure.

of points in plane that is vertical to the axial line are the same. Hence, the three-dimensional permeability tensor of CJRM is converted to two-dimensional permeability tensor. According to the transformation rule of the tensor coordinate system and the invariance of tensor, the major and minor principle permeability coefficients (PPCs) of CJRM during three-time cyclic loading and unloading of confinement pressure are calculated, and the curves of the major and minor PPCs during three-time cyclic loading and unloading of confinement pressure are drawn in Figure 9 and 10.

According to Figures 9 and 10, in the first loading phase of confinement pressure, the major and minor PPCs of CJRM decrease significantly with the increase of confinement pressure, and with the unloading of confinement pressure, the values of the major and minor PPCs grow 


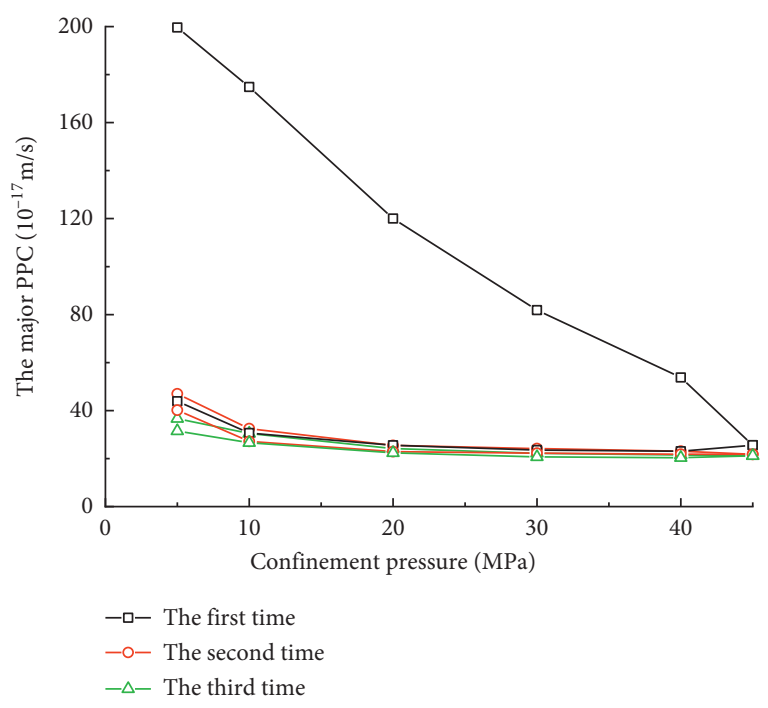

Figure 9: The curves of the major PPC during cyclic loading and unloading of confinement pressure.

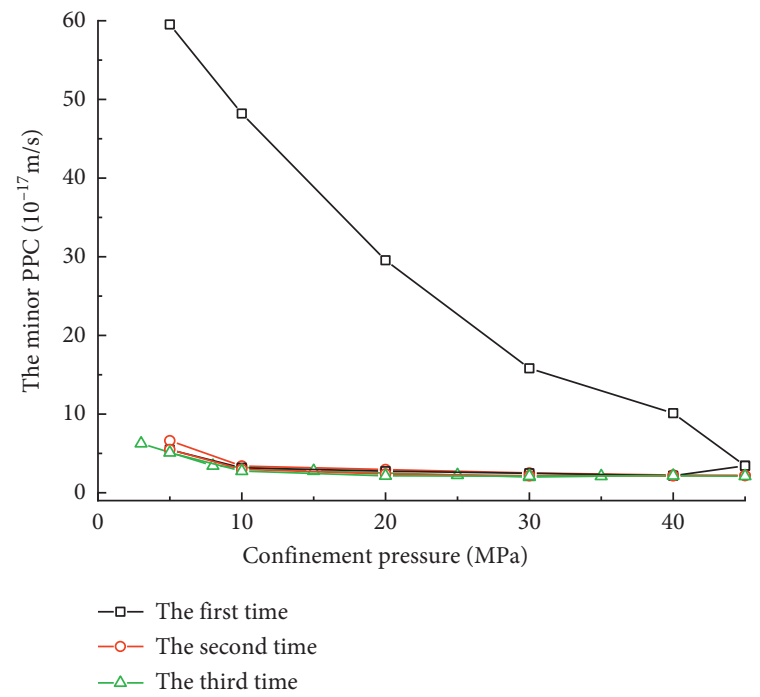

Figure 10: The curves of the minor PPC during cyclic loading and unloading of confinement pressure.

slightly. In the following stages of loading and unloading of confinement pressure, the relationship curves between the major and minor PPCs and confinement pressure are nearly identical, and the major and minor PPCs keep stable, with low value.

\section{Conclusions}

In this work, an innovative method is proposed to prepare artificial CJRM with different columnar dip angles, and laboratory physical model tests are conducted to investigate the anisotropic permeability and porosity characteristics of the prepared artificial CJRM. In the physical model experiment, the permeability and porosity of artificial CJRM with different columnar dip angles is measured during three times cyclic loading and unloading of confinement pressure.
Based on the results of the physical model experiment, the anisotropic permeability and porosity change law of artificial CJRM during cyclic loading and unloading of confinement pressure is researched. Then, the internal mechanism analysis of the relationship between anisotropic permeability of CJRM and cyclic loading and unloading of confinement pressure is conducted based on the measured porosity. After that, based on laboratory model tests, mathematical models for calculating the permeability tensor of CJRM during cyclic loading and unloading of confinement pressure are developed based on theory of Equivalent Continuum Media Model. The main research findings of the research are drawn as follows:

(1) In the first loading phase of confinement pressure, the impacts of confinement pressure on anisotropic permeability of artificial CJRM, porosity, and the major and minor PPCs are significant, while in the following stages of confinement pressure loading and unloading, the change of them is small, with stable value.

(2) Due to the existence of columnar joint structure, the decreasing magnitude of artificial CJRM permeability with loading of confinement pressure is larger than that of intact artificial rock masses, while, during confinement pressure unloading, permeability of artificial CJRM is more difficult to recover to original value than that of intact artificial rock masses.

(3) Permeability of artificial CJRM with large columnar dip angle is higher than that of artificial CJRM with small columnar dip angle. During the first-time loading of confinement pressure, the permeability anisotropy of artificial CJRM decreases. In the following stages of loading and unloading of confinement pressure, the permeability anisotropy of artificial CJRM is nonsignificant.

(4) Due to the existence of columnar joint structure, artificial CJRM is easier to be compacted than that of intact artificial rock masses with loading of confinement pressure, and the compacted status of artificial CJRM keeps during unloading of confinement pressure.

\section{Data Availability}

In this paper, all data, models, and codes used during the study appear in the submitted article.

\section{Conflicts of Interest}

The authors declare that they have no conflicts of interest.

\section{Authors' Contributions}

Zhiming Chao and Guotao Ma contributed to conceptualization; methodology; software; writing and original draft preparation; and review and editing of the paper. Xiewen $\mathrm{Hu}$ contributed to data validation; supervision; project administration; and funding acquisition. Zhiming Chao 
contributed to formal analysis and investigation. Yuzhe Zhu, Zhiming Chao, and Guotao Ma visualized the study.

\section{Acknowledgments}

This study was supported by the National Key Research and Development Program of China (2018YFC1505404).

\section{References}

[1] M. Bahaaddini, P. Hagan, R. Mitra, and B. Hebblewhite, "Numerical study of the mechanical behavior of nonpersistent jointed rock masses," International Journal of Geomechanics, vol. 16, no. 1, Article ID 04015035, 2016.

[2] Q. Fan, X. Feng, W. Weng, Y. Fan, and Q. Jiang, "Unloading performances and stabilizing practices for columnar jointed basalt: a case study of Baihetan hydropower station," Journal of Rock Mechanics and Geotechnical Engineering, vol. 9, no. 6, pp. 1041-1053, 2017.

[3] Y. H. Hatzor, X.-T. Feng, S. Li, G. Yagoda-Biran, Q. Jiang, and $\mathrm{L}$. Hu, "Tunnel reinforcement in columnar jointed basalts: the role of rock mass anisotropy," Tunnelling and Underground Space Technology, vol. 46, pp. 1-11, 2015.

[4] C. Jin, S. Li, and J. Liu, "Anisotropic mechanical behaviors of columnar jointed basalt under compression," Bulletin of Engineering Geology and the Environment, vol. 77, no. 1, pp. 317-330, 2016.

[5] Z.-G. Shan and S.-J. Di, "Loading-unloading test analysis of anisotropic columnar jointed basalts," Journal of Zhejiang University SCIENCE A, vol. 14, no. 8, pp. 603-614, 2013.

[6] Y.-X. Xiao, X.-T. Feng, B.-R. Chen, G.-L. Feng, Z.-B. Yao, and L.-X. Hu, "Excavation-induced microseismicity in the columnar jointed basalt of an underground hydropower station," International Journal of Rock Mechanics and Mining Sciences, vol. 97, pp. 99-109, 2017.

[7] J.-S. Zhao, X.-T. Feng, Q. Jiang, and Y.-Y. Zhou, "Microseismicity monitoring and failure mechanism analysis of rock masses with weak interlayer zone in underground intersecting chambers: a case study from the Baihetan Hydropower Station, China,” Engineering Geology, vol. 245, pp. 44-60, 2018.

[8] S. Demirel, J. Irving, and D. Roubinet, "Comparison of REV size and tensor characteristics for the electrical and hydraulic conductivities in fractured rock," Geophysical Journal International, vol. 216, no. 3, pp. 1953-1973, 2019.

[9] L. Xia, Y. Zheng, and Q. Yu, "Estimation of the REV size for blockiness of fractured rock masses," Computers and Geotechnics, vol. 76, pp. 83-92, 2016.

[10] J. Cheng, H. Zhang, and Z. Wan, "Numerical simulation of shear behavior and permeability evolution of rock joints with variable roughness and infilling thickness," Geofluids, vol. 2018, Article ID 1869458, 11 pages, 2018.

[11] S.-H. Chen, "Comprehensive application of the composite element method: numerical test of jointed rock masses," in Computational Geomechanics and Hydraulic Structures, Springer, Berlin, Germany, 2019.

[12] Z. Gurocak and S. Alemdag, "Assessment of permeability and injection depth at the Atasu dam site (Turkey) based on experimental and numerical analyses," Bulletin of Engineering Geology and the Environment, vol. 71, no. 2, pp. 221-229, 2012.

[13] G. Preisig, E. Eberhardt, V. Gischig et al., "Development of connected permeability in massive crystalline rocks through hydraulic fracture propagation and shearing accompanying fluid injection," Geofluids, vol. 15, no. 1-2, pp. 321-337, 2015.
[14] J. Sun and Z. Zhao, "Effects of anisotropic permeability of fractured rock masses on underground oil storage caverns," Tunnelling and Underground Space Technology, vol. 25, no. 5, pp. 629-637, 2010.

[15] T. Jiang, J. F. Shao, W. Y. Xu, and C. B. Zhou, "Experimental investigation and micromechanical analysis of damage and permeability variation in brittle rocks," International Journal of Rock Mechanics and Mining Sciences, vol. 47, no. 5, pp. 703-713, 2010.

[16] P. S. Lang, A. Paluszny, and R. W. Zimmerman, "Permeability tensor of three-dimensional fractured porous rock and a comparison to trace map predictions," Journal of Geophysical Research: Solid Earth, vol. 119, no. 8, pp. 6288-6307, 2014.

[17] R. Liu, B. Li, Y. Jiang, and N. Huang, "Review: mathematical expressions for estimating equivalent permeability of rock fracture networks," Hydrogeology Journal, vol. 24, no. 7, pp. 1623-1649, 2016.

[18] M.-N. Vu, A. Pouya, and D. M. Seyedi, "Modelling of steadystate fluid flow in 3D fractured isotropic porous media: application to effective permeability calculation," International Journal for Numerical and Analytical Methods in Geomechanics, vol. 37, no. 14, pp. 2257-2277, 2013.

[19] M. Vu, S. Nguyen, Q. To, and N. Dao, "Theoretical predicting of permeability evolution in damaged rock under compressive stress," Geophysical Journal International, vol. 209, pp. 1352-1361, 2017.

[20] H. Ji, S.-H. Chen, and I. Shahrour, "A revised solution of equivalent permeability tensor for discontinuous fractures," Journal of Hydrodynamics, vol. 24, no. 5, pp. 711-717, 2012.

[21] P.-T. Wang, T.-H. Yang, T. Xu, Q.-L. Yu, and H.-L. Liu, “A model of anisotropic property of seepage and stress for jointed rock mass," Journal of Applied Mathematics, vol. 2013, Article ID 420536, 19 pages, 2013.

[22] L. Zhang, L. Xia, and Q. Yu, "Determining the REV for fracture rock mass based on seepage theory," Geofluids, vol. 2017, Article ID 4129240, 8 pages, 2017.

[23] X. F. Deng, J. B. Zhu, S. G. Chen, Z. Y. Zhao, Y. X. Zhou, and J. Zhao, "Numerical study on tunnel damage subject to blastinduced shock wave in jointed rock masses," Tunnelling and Underground Space Technology, vol. 43, pp. 88-100, 2014.

[24] G. Meng, C. Detournay, and P. Cundall, "Continuum/discrete numerical simulation of columnar basalt in large-scale underground excavations," in Proceedings of the 50th US Rock Mechanics/Geomechanics Symposium, American Rock Mechanics Association, Houston, TX, USA, June 2016.

[25] L. Wang, X. H. Zhong, J. S. Yang et al., "Finite element simulation of surface micro-indentation behavior of yttria stabilized zirconia thermal barrier coatings with microstructural characteristic of columnar grains and sub-grains based on a nonlinear contact model," Computational Materials Science, vol. 82, pp. 244-256, 2014.

[26] L. Goehring and S. W. Morris, "Scaling of columnar joints in basalt," Journal of Geophysical Research: Solid Earth, vol. 113, no. B10, 2008.

[27] W.-M. Xiao, R.-G. Deng, Z.-B. Zhong, X.-M. Fu, and C.-Y. Wang, "Experimental study on the mechanical properties of simulated columnar jointed rock masses," Journal of Geophysics and Engineering, vol. 12, no. 1, pp. 80-89, 2014.

[28] X.-W. Jiang, X.-S. Wang, and L. Wan, "Semi-empirical equations for the systematic decrease in permeability with depth in porous and fractured media," Hydrogeology Journal, vol. 18, no. 4, pp. 839-850, 2010.

[29] A. Lisjak, P. Kaifosh, L. He, B. S. A. Tatone, O. K. Mahabadi, and G. Grasselli, "A 2D, fully-coupled, hydro-mechanical, 
FDEM formulation for modelling fracturing processes in discontinuous, porous rock masses," Computers and Geotechnics, vol. 81, pp. 1-18, 2017.

[30] G. Hetényi, B. Taisne, F. Garel, É. Médard, S. Bosshard, and H. B. Mattsson, "Scales of columnar jointing in igneous rocks: field measurements and controlling factors," Bulletin of Volcanology, vol. 74, no. 2, pp. 457-482, 2012.

[31] J. Browning, P. Meredith, and A. Gudmundsson, "Coolingdominated cracking in thermally stressed volcanic rocks," Geophysical Research Letters, vol. 43, no. 16, pp. 8417-8425, 2016.

[32] H. Wang, W. Xu, and J. Zuo, "Compact rock material gas permeability properties," Physica B: Condensed Matter, vol. 449, pp. 10-18, 2014a. 